\title{
PENGEMBANGAN MEDIA PAKAPINDO (PAPAN KANTONG PINTAR DORAEMON) PADA MATERI HUKUM-HUKUM DASAR KIMIA UNTUK MENINGKATKAN MOTIVASI BELAJAR SISWA KELAS X DI MA RAUDHATUSYSYUBBAN
}

\section{The Development Of Pakapindo (Doraemon Smart Pocket Board) Media On Basic Chemical Laws To Increase Student's Motivation Learning Class X In MA Raudhatusysyuban}

\author{
Dina Zairida, Okviyoandra Akhyar, Raden Roro Ariessanty Alicia Kusuma \\ Wardhani \\ Program Studi Pendidikan Kimia Fakultas Keguruan dan Ilmu Pendidikan \\ Universitas Islam Kalimantan (Uniska) Muhammad Arsyad Al Banjari, Banjarmasin \\ email: dinazairida@gmail.com
}

\begin{abstract}
Abstrak. Hukum dasar kimia merupakan salah satu materi kimia yang mempunyai karakteristik yang bersifat kongkrit sampai yang bersifat abstrak, bersifat rill dan dekat dengan kehidupan sehari-hari, selain itu juga membutuhkan pemahaman konsep yang tinggi dan kemampuan matematika yang baik, sehingga membuat kurangnya motivasi siswa. Pada penelitian ini dikembangkan media pakapindo untuk membantu meningkatkan motivasi belajar siswa pada materi hukum-hukum dasar kimia. Jenis penelitian yang digunakan adalah penelitian pengembangan dengan metode Research and Development $(R \& D)$ dengan menggunakan langkah 1 sampai langkah 6. Populasi yang digunakan adalah kelas X MA Raudhatusysyuban dengan sampel kelas X MIA yang berjumlah 27 orang siswa. Selain menguji kelayakan media, penelitian ini juga menguji efektivitas media terhadap motivasi belajar. Hasil penelitian pengembangan media pakapindo ditinjau dari analisis kelayakan media pakapindo dimana pada validasi media oleh ahli memperoleh penilaian sebesar 67,7 berada pada rentang $X>63$ sehingga termasuk kedalam kategori sangat baik,uji keterbacaan media pakapindo memperoleh persentase $80 \%$ ada pada kategori sangat baik, dan uji respon siswa diperoleh persentase 70,8 ada pada kategori sangat baik. Pada uji kelompok kecil dengan sampel 10 orang siswa di SMAN 1 Sungai Tabuk diperoleh persentase sebesar $63 \%$ sedangkan uji kelompok besar di MA Raudhatusysyuban 94,3\% dengan peningkatan motivasi belajar siswa sebesar $30,82 \%$.
\end{abstract}

Kata kunci : Hukum Dasar Kimia, Motivasi Belajar, Pakapindo

Abstract. Basic chemical law is one of the chemical material that has characteristics that are concrete to abstract nature, real and close to everyday life, beside that it also requires high understanding of concepts and good mathematical skill, this making stundent lack of motivation. In this research pakapindo media was developed to help increase student's learning motivation in the material of basic chemical laws. The type of research used is development research with the Research and Development $(R \& D)$ method using steps 1 through step 6. The population used is class X MA Raudhatusysyuban with samples of class X MIA, amounting to 27 students. In addition to testing the feasibility of media, this study also tested the effectiveness of the media on 
learning motivation. The results of pakapindo's media development research are reviewed from Pakapindo's media feasibility analysis where the media validation by experts received an assessment of 67,7 in the $X>63$ range so that it was included in the excellent category, Pakapindo's media readability test obtained an $80 \%$ percentage in the very good category, and student response tests obtained a percentage of 70,8\% in the excellent category. In the small group test with a sample of 10 students at SMAN 1 Sungai Tabuk a percentage of $63 \%$ was obtained while the large group test MA Raudhatusysyuban 94,3\% with an increase in student learning motivation by $30,82 \%$.

Keyword : Chemical Basic Law, Motivation to Learn, Pakapindo

\section{PENDAHULUAN}

Kualitas sumber daya manusia merupakan salah satu penentu kemajuan suatu bangsa. Terciptanya sumber daya manusia yang berkualitas adalah berawal dari generasi yang terdidik, oleh karena itu peningkatan kualitas pendidikan perlu ditingkatkan agar terciptanya generasi penerus yang mampu mengembangkan sumber daya manusia yang berkualias (Haryono, 2014). Salah satu upaya pemerintah untuk meningkatkan kualitas pendidikan adalah dengan menggunakan kurikulum 2013. Kurikulum 2013 bertujuan untuk mempersiapkan anak-anak Indonesia agar memiliki kemampuan hidup sebagai pribadi dan warga negara yang beriman, produktif, kreatif, inovatif serta mampu berkontribusi pada kehidupan bermasyarakat. Beberapa sekolah menengah atas (SMA/MA) di Kabupaten Banjar sudah menggunakan kurikulum 2013 diantaranya MA Raudhatusysyuban.

Penggunaan kurikulum 2013 di sekolah menuntut tenaga pendidik untuk lebih meningkatkan kinerjanya baik berupa pengetahuan, keterampilan dan sikap, ketiga aspek tersebut sangat diperlukan agar pendidik dapat melaksanakan kurikulum 2013 sesuai dengan amanat kurikulum. Tugas pendidik bukan hanya sebagai fasilitator pada saat pembelajaran, tetapi tugas pendidik juga sebagai motivator untuk membangkitkan semangat dan kemauan siswa dalam mengeksplorasi materi belajar sebanyak mungkin. Motivasi yang cukup akan membangkitkan semangat siswa untuk belajar secara maksimal.

Motivasi adalah faktor yang mendorong seseorang untuk melaksanakan tugasnya sebagai siswa dengan penuh semangat sehingga meningkatkan hasil belajar, perlu dilakukan inovasi pembelajaran yang memperlihatkan kesesuaian antara model dan media pendukung dengan karakteristik materi yang disampaikan agar tujuan pembelajaran dapat tercapai seperti yang diharapkan. Untuk mengatasi hal ini dibutuhkan medi pembelajaran yang membuat siswa lebih aktif dalam kegiatan belajar mengajar untuk mencapai hasil belajar yang maksimal (Mahrus, 2015).

Berdasarkan hasil observasi dengan guru di MA Raudhatusysyuban diketahui siswa kurang aktif terhadap pembelajaran kimia dikarenakan masih kurangnya penggunaan media pembelajaran. Adapun media yang sering digunakan pada saat pembelajaran adalah buku cetak, untuk media pakapindo belum pernah dilakukan pada saat pembelajaran. Salah satu materi yang kurang dikuasai oleh peserta didik adalah hukum-hukum dasar kimia, hal ini disebabkan materi hukum-hukum dasar kimia mempunyai karakteristik yaitu bersifat kongkrit sampai yang bersifat abstrak, bersifat ril 
dan dekat dengan kehidupan sehari-hari, selain itu membutuhkan pemahaman konsep yang tinggi dan kemampuan matematika yang baik dalam penyelesaian soal-soalnya (Sehingga membuat kurangnya ketertarikan siswa terhadap pembelajaran kimia di kelas.

Penggunaan media pakapindo dilatar belakangi faktor kesesuaian terhadap materi, serta adanya faktor kesesuaian gaya belajar yang biasanya guru menerapkan metode pembelajaran kurang menarik. Media pakapindo merupakan media yang di buat berbentuk papan berkantong serta satu buah keranjang dengan tujuan dapat melatih keaktifan menjawab siswa dan mengetahui motivasi siswa dalam mengikuti pembelajaran. Media permainan pakapindo merupakan media yang dikemas untuk melatih keaktifan menjawab siswa dan mengetahui motivasi siswa dalam mengikuti pembelajaran di kelas. Permainan ini bisa digunakan pada materi yang berupa hitungan. Media pakapindo merupakan media mengajar dengan melemparkan satu buah dadu, dimna angka dadu berhenti maka siswa akan diberikan pertanyaan pada kantong atau keranjang sesuai dengan angka dadu yang keluar. Media pakapindo ini memiliki beberapa kelebihan pada pengembangannya dalam pembelajaran, yaitu (1) pakapindo merupakan suatu permainan yang menyenangkan dan juga tidak membosankan, (2) memungkinkan adanya keterlibatan dari siswa untuk belajar, (3) mampu melatih berpikir kritis siswa, (4) terlihat adanya suatu keinginan untuk menguji kemampuan siswa yang satu dengan yang lain, (5) selalu terus berusaha mempertahankan jawaban pertanyaan agar dapat memperoleh nilai yang ditawarkan.

\section{METODE PENELITIAN}

Penelitian pengembangan (Research and Development/ R\&D) media pakapindo menggunakan desain Brog and Gall langkah 1 - 6 (Lindasari, 2016) Analisis data yang digunakan untuk uji efektivitas media terhadap motivasi belajar siswa menggunakan uji statistic wilcoxon berbantuan software SPSS tipe v16,0.

\section{HASIL DAN PEMBAHASAN}

Penelitian ini dilakukan di MA Raudhatussyuban pada tanggal 27 April 2019 sampai dengan selesai. Populasinya adalah semua siswa - siswi kelas X dengan sampel kelas X MIA. Penelitian ini merupakan penelitian R\&D (Research and Development) dengan produk yang dihasilkan media pakapindo. Pengembangan produk menggunakan desain Brog and Gall yang dilakukan dari langkah pertama sampai langkah keenam yaitu pendahuluan sampai uji produk tahap luas ke sekolah terhadap motivasi belajar siswa. 

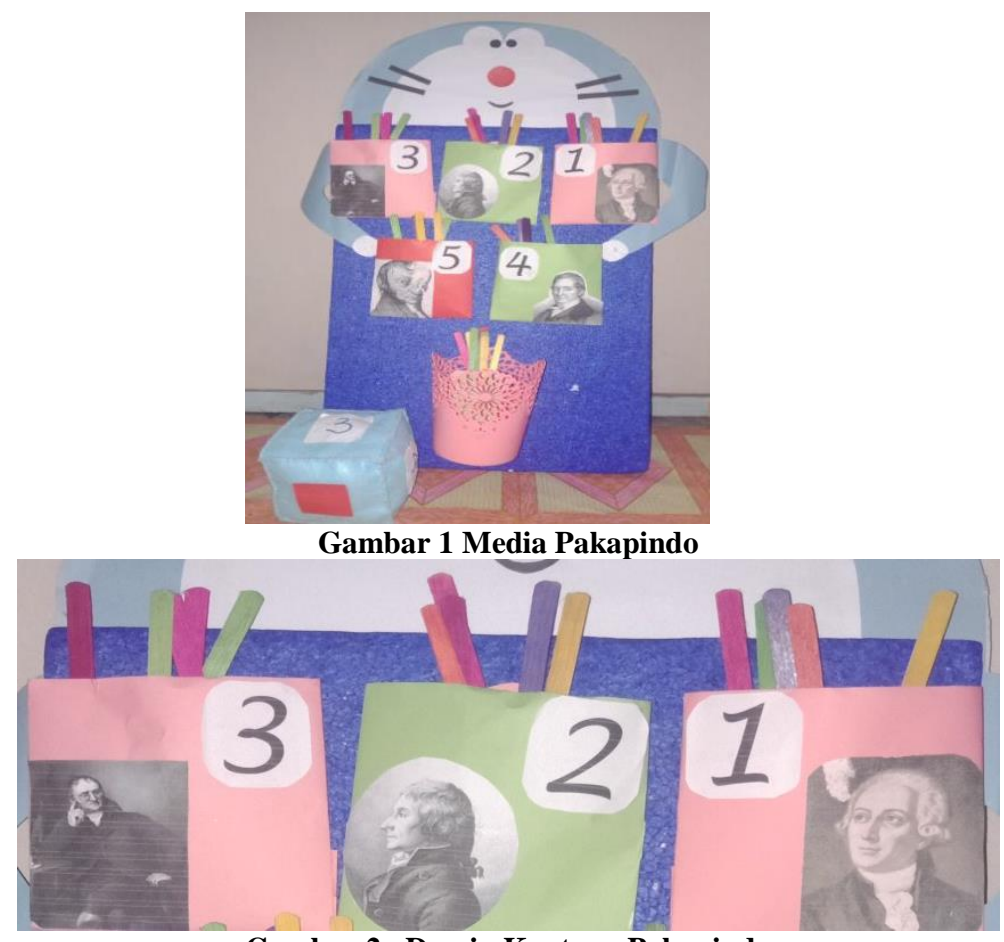

Gambar 2. Desain Kantong Pakapindo

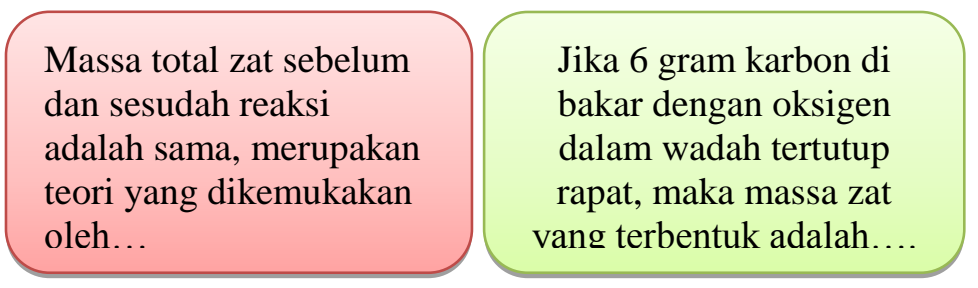

Gambar 3. Isi kartu soal

Tabel 1. Pengembangan model pakapindo

\begin{tabular}{lll}
\hline Aspek penelitian & $\begin{array}{l}\text { Penelitian oleh (Agustina, } \\
\text { 2017) }\end{array}$ & $\begin{array}{l}\text { Penelitian } \\
\text { dilakukan sekarang }\end{array}$ \\
\hline Jenis Penelitian & Penelitian Pengembangan & $\begin{array}{l}\text { Penelitian } \\
\text { Pengembangan }\end{array}$ \\
\hline Produk & Media Pakapindo & Media Pakapindo \\
\hline Model Penelitian & ADDIE & Borg \& Gall \\
\hline Peraturan Permainan & Media pakapindo memiliki & $\begin{array}{l}\text { Media pakapindo } \\
\text { berbahan steroform } \\
\text { enam kantong yang berisi }\end{array}$ \\
& $\begin{array}{l}\text { pertanyaan dimana perwakilan } \\
\text { dari salah satu siswa }\end{array}$ & kantong dan satu buah \\
\hline
\end{tabular}


Dalton : Jurnal Pendidikan Kimia dan Ilmu Kimia, Volume 2 Nomor 2, November 2019

\begin{tabular}{lll}
\hline melemparkan dadu dan & keranjang yang berisi \\
mengambil pertanyaan pada & pertanyaan dengan \\
kantong yang terdapat pada & bantuan satu buah \\
media pakapindo sesuai & dadu, dimana siswa \\
dengan angka dadu yang & diminta berkelompok \\
keluar kemudian didiskusikan & dan perwakilan setiap \\
dengan kelompok masing - & kelompok \\
masing, setelah selesai & melemparkan dadu, \\
berdiskusi perwakilan dari & jika dadu yang jatuh \\
kelompok tampil ke depan & menunjukkan angka \\
untuk membacakan hasil & maka siswa akan \\
laporannya menjawab pertanyaan & pada kantong dan \\
& mendapat poin 10 \\
& sedangkan jika dadu \\
& jatuh menunjukkan \\
& kertas merah maka \\
& siswa akan menjawab \\
& pertanyaan pada \\
keranjang dan & mendapat poin 20 \\
\hline
\end{tabular}

Tabel 2. Hasil validasi media pakapindo

\begin{tabular}{cccc}
\hline Aspek & Validator (I) & Validator (II) & Validator (III) \\
\hline Isi & 16 & 17 & 20 \\
Bahasa & 23 & 24 & 25 \\
Sajian & 8 & 8 & 10 \\
Kegrafi & 16 & 16 & 20 \\
sa & & & \\
n & & 65 & 75 \\
\hline Total & 63 & Sangat Baik & Sangat Baik \\
\hline Hasil & Sangat Baik & A & A \\
\hline Kriteria & A & 67,7 &
\end{tabular}

Berdasarkan tabel 2 diperoleh nilai rata-rata 67,7 pada tabel penentuan kriteria skala likert berada pada rentang $X>63$ sehingga termasuk kriteria sangat baik (A). Hasil persentase dari angket keterbacaan media pakapindo oleh siswa pada uji coba produk dapat dilihat pada gambar 4 


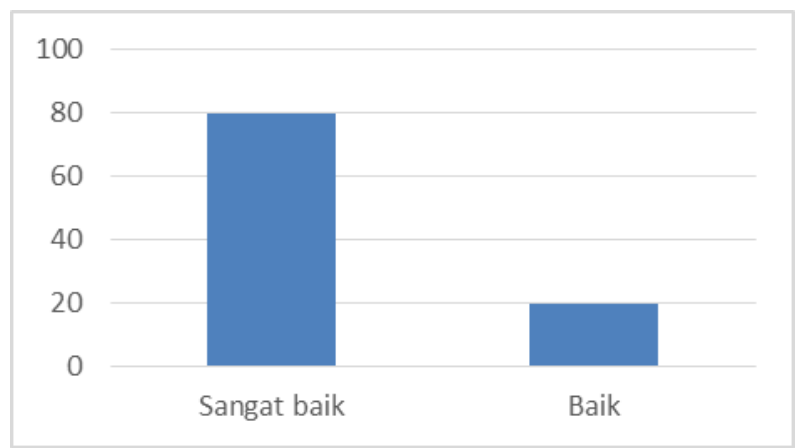

Gambar 4. Persentase angket keterbacaan

Berdasarkan gambar 4 diperoleh nilai $80 \%$ untuk kategori sangat baik dan 20\% untuk kategori baik. Hasil uji coba pemakaian media pakapindo pada pembelajaran materi hukum-hukum dasar kimia melalui angket respon siswa dapat dilihat pada tabel 3 .

Tabel 3 Persentase hasil angket respon siswa

\begin{tabular}{cc}
\hline Persentase $(\%)$ & Kategori \\
\hline 70,8 & Sangat baik \\
57,7 & Baik \\
\hline
\end{tabular}

Berdasarkan data hasil validasi kelayakan media pakapindo dari validator, hasil angket keterbacaan media pakapindo oleh siswa pada uji coba produk dan hasil angket respon pembelajaran menggunakan media pakapindo oleh siswa pada uji coba pemakaian produk maka dapatdisimpulkan bahwa media pakapindo layak digunakan sebagai media pembelajaran pada materi hukum-hukum dasar kimia. Respon siswa pada uji coba kelompok kecil dengan sampel 10 orang siswa di SMAN 1 Sungai Tabuk dapat dilihat pada tabel 4 .

Tabel 4. Uji coba skala kecil

\begin{tabular}{ccccc}
\hline N & Validator & Nilai & Hasil & Kriteria \\
\hline 1. & I & 75 & Sangat Baik & A \\
\hline 2. & II & 60 & Baik & B \\
\hline 3. & III & 55 & Baik & B \\
\hline 4. & IV & 60 & Baik & B \\
\hline 5. & V & 73 & Sangat Baik & A \\
\hline 6. & VI & 56 & Baik & B \\
\hline 7. & VII & 70 & Sangat Baik & A \\
\hline 8. & VIII & 60 & Baik & B \\
\hline 9. & IX & 65 & Sangat Baik & B \\
\hline 10 & X & 55 & Baik & A \\
\hline
\end{tabular}


Berdasarkan uji coba skala kecil diperoleh nilai rata-rata 63 yang diperoleh pada tabel penentuan kriteria skala likert berada pada rentang $X>63$ sehingga termasuk kriteria sangat baik (A) dengan persentase 63\%. Validasi isi angket motivasi belajar siswa dari 50 butir angket yang diuji diperoleh 40 butir angket yang valid dan 15 butir angket yang tidak valid. Berdasarkan hasil uji validitas isi angket motivasi diperoleh persentase sebesar 94,5\% ada pada kriteria sangat baik. Adapun hasil uji validasi isi angket motivasi sebagai berikut :

Tabel 5. Hasil uji validitas isi angket motivasi

\begin{tabular}{lc}
\hline \multicolumn{1}{c}{ Indikator } & Skor \\
\hline Menunjukkan minat belajar & 29,9 \\
Semangat, tekun, mandiri, ulet dalam & 23,8 \\
pembelajaran & \\
Senang terhadap guru kimia & 10 \\
Senang kerja kelompok & 19,6 \\
Berprestasi dalam belajar & 10,9 \\
\hline Total & 94,2 \\
\hline Persentase & $94,2 \%$ \\
\hline
\end{tabular}

Perhitungan rata-rata hasil pengisian angket motivasi belajar oleh siswa sebelum menggunakan media pakapaindo dan setelah menggunakan media pakapindo adalah sebagai berikut :

Tabel 6. Rata - rata skor angket motivasi belajar siswa sebelum dan setelah menggunakan media pakapindo

\begin{tabular}{lll}
\hline \multicolumn{1}{c}{$\begin{array}{c}\text { Nilai menggunakan } \\
\text { media }\end{array}$} & Sebelum & Setelah \\
\hline Terendah & 84 & 139 \\
Tertinggi & 123 & 188 \\
\hline Rata-rata & 109,67 & 158,52 \\
\hline Selisih & \multicolumn{3}{|}{48,85} \\
\hline Persentase & $30,82 \%$ \\
\hline
\end{tabular}

Berdasarkan tabel di atas didapatkan hasil bahwa nilai rata-rata sebelum dan setelah menggunakan media pakapindo hasil motivasi belajar siswa diketahui nilai ratarata sebelum menggunakan media 109,67, sedangkan setelah menggunakan media nilai rata-rata adalah 158,52 . Perbedaan ini terjadi karena adanya penggunaan media pakapindo yang mempengaruhi motivasi belajar yang dicapai, sehingga didapat persentase sebesar $30,82 \%$. 
Pada analisis uji statistik dihitung berdasarkan hasil angket motivasi sebelum dan setelah menggunakan media pakapindo. Berdasarkan data yang diperoleh, angket motivasi di uji validitas isi terlebih dahulu untuk mengetahui butir angket mana saja yang valid dan bisa digunakan untuk mengukur motivasi belajar. Setelah mendapatkan nilai sebelum dan setelah menggunakan media pakapindo maka selanjutnya dilakukan uji statistic wilcoxon non parametric, digunakan uji wilcoxon dikarenakan sampel yang ada di sekolah kurang dari 30 siswa, untuk uji wilcoxon digunakan software SPSS 16.0 for windows, diperoleh nilai sig 0,000 dai penelitian tersebut dihasilkan bahwa sig < 0,005 maka H0 ditolak dan H1 diterima dengan kenaikan motivasi sebesar 30,82\% menggunakan media pakapindo pada materi hukum-hukum dasar kimia dengan taraf kepercayaan 95\% selain itu juga didukung dengan nilai kognitif siswa yang melebihi batas $\mathrm{kkm}$ sehingga media pakapindo sangat layak digunakan untuk meningkatkan motivasi belajar siswa.

Penelitian menggunakan media pakapindo ini untuk meningkatkan motivasi belajar siswa didukung oleh hasil penelitian yang telah dilakukan oleh (Wulandari dkk, 2018) tentang "Pengembangan Media Pakapindo Sebagai Media Pembelajaran Untuk Melatih Keaktifan Menjawab Dan Meningkatkan Hasil Belajar Siswa Pada Pembelajaran Tematik" disampaikan bahwa media pakapindo yang dikembangkan memiliki kualitas sangat baik. Pada uji coba kelompok kecil diperoleh persentase sebanya 97,5\%, sedangkan uji coba kelompok besar diperoleh persentase 98\% dengan kategori sangat baik. Sedangkan penelitian Faridha (2017) tentang "Penerapan media kantong ajaib doraemon dengan model omeake untuk meningkatkan kemampuan membuat kalimat tanya siswa" dengan hasil penelitian ini menunjukkan pada siklus 1 kemampuan membuat kalimat tanya dengan menggunakan media kantong ajaib doraemon dengan model omeake mencapai $63 \%$ siswa tuntas belajarnya dan meningkat menjadi $89 \%$ pada siklus II. Berdasarkan hasil penelitian dapat disimpulkan bahwa penerapan media kantong ajaib doraemon dengan model omeake dapat meningkatkan kemampuan belajar siswa.

\section{SIMPULAN}

Berdasarkan hasil dan pembahasan maka dapat diambil kesimpulan bahwa media pakapindo efektif dapat meningkatkan motivasi belajar siswa untuk materi hukumhukum dasar kimia hal ini ditunjukkan dengan adanya peningkatan 30,82\%. Hasil penilaian media pakapindo ini secara keseluruhan sangat baik dan layak digunakan sebagai bahan pembelajaran.

\section{DAFTAR RUJUKAN}

Agustina, F. (2017) Pengembangan Media Pakapindo Sebagai Media Pembelajaran Untuk Melatih Keaktifan Menjawab Dan Meningkatkan Hasil Belajar Siswa Pada Pembelajaran Tematik. Skripsi Jurusan Pendidikan Guru Sekolah Dasar Universitas Muhammadiyah Malang, Malang

Ambarwati, T., Haryono., Dan Sukardjo, JS., (2014) Penerapan Pembelajaran Numbered Heads Together (NHT) Dilengkapi Media Macromedia Flash Untuk Meningkatkan Kreativitas Dan Prestasi Belajar Siswa Pada Materi Hidrolisis 
Dalton : Jurnal Pendidikan Kimia dan Ilmu Kimia, Volume 2 Nomor 2, November 2019

Garam Kelas XI IPA 4 SMA Negeri 2 Karanganyar Tahun Pelajaran 2012/2013, Jurnal Pendidikan Kimia, 3 (1), 58-64

Faridha, D. (2017) Penerapan Media Kantong Ajaib Doraemon Dengan Model Omeake Untuk Meningkatkan Kalimat Tanya Siswa. Skripsi Jurusan Pendidikan Guru Sekolah Dasar Universitas Negeri Surabaya. Surabaya.

Lindasari, A. (2016). Pengembangan Modul Pembelajaran Kimia Berbasis Pedagogical Content Knowledge Untuk Materi Pokok Struktur Atom Terhadap Kemandirian Belajar Siswa. Skripsi. Program Studi Pendidikan Kimia Universitas Islam Kalimantan Muhammad Arsyad Al - Banjari. Banjarmasin

Mahrus, M. (2015) Meningkatkan Motivasi Belajar Siswa Melalui Media Pembelajaran Audio Visual Pada Mata Pelajaran Akhlak Di Madrasah Aliyah Negeri (MAN) Bondowoso. Skripsi. Jurusan Pendidikan Agama Islam Universitas Islam Negeri Maulana Malik Ibrahim. Malang

Wulandari, I.A., Mashuri, M. T., Dony, N. (2018). Pengaruh Media Kotak Kartu Misterius (Kokami) Terhadap Hasil Belajar Siswa Pada Materi Pokok HukumHukum Dasar Kimia di SMA Negeri 12. Dalton: Jurnal Pendidikan Kimia dan Ilmu Kimia. 1(2), 1-5. 